\title{
PENG BLOCK IN ADDITION TO LIA COULD REPRESENT A VALUABLE POST-OPERATIVE ANALGESIA IN PATIENTS UNDERGOING HIP REPLACEMENT: A CASE REPORT
}

P. Fusco ${ }^{1}$, L. Gentili ${ }^{2}$, E. Di Martino ${ }^{3}$, V. De Paolis ${ }^{2}$, F. De Sanctis ${ }^{2}$, C. Ciccone ${ }^{4}$, A. Ciccozzi ${ }^{5}$, F. Lentini ${ }^{6}$, and F. Marinangeli ${ }^{5}$

${ }^{1}$ University of L'Aquila, Department of Anaesthesia and Intensive Care Unit- San Salvatore Academic Hospital of L'AquilaL'Aquila- Italy, ${ }^{2}$ University of L'Aquila, Department of Life-Health \& Environmental Sciences- L'Aquila, Italy, ${ }^{3}$ University of Chieti,

Department of Anaesthesia, Resuscitation, Intensive and Pain Care-Chieti- Italy, ${ }^{4}$ Humanitas University- Milano- Italy, ${ }^{5}$ University of L'Aquila, Department of Life-Health and Environmental Sciences- L'Aquila- Italy, ${ }^{6}$ ASST Lariana, Sant'Anna Hospital in Como, Department of Anesthesia, Resuscitation and Emergency

\section{BACKGROUND AND AIMS}

PENG (PEricapsular Nerve Group) block is novel ultrasound-guided technique, which is suggested as an efficient choice for treating pain, in patients with hip fracture.

\section{METHODS}

A 75-year-old woman, ASA II, undergoing right hip replacement. In history COPD, hypertension and glaucoma. Written informed consent to the treatment was obtained. Prior routine monitoring, ultrasoundguided PENG block was performed using a lowfrequency convex probe (3-5 MHz) and a 21-gauge, 100 $\mathrm{mm}$, echogenic needle was inserted in the fascial plane between the psoas tendon and the pubic branches posteriorly. Then, $20 \mathrm{ml}$ solution containing $75 \mathrm{mg}$ of isobaric levobupivacaine $0.375 \%$ and dexamethasone $4 \mathrm{mg}$ was injected. Subarachnoid block was performed by injecting $12 \mathrm{mg}$ of $0.5 \%$ isobaric levobupivacaine at L3-L4 level. Before closing the surgical wound, a $20 \mathrm{ml}$ solution containing $75 \mathrm{mg}$ of levobupivacaine $0,375 \%$, $30 \mathrm{mg}$ of ketorolac tromethamine and $0.1 \mathrm{mg}$ of adrenaline (LIA) was injected by the surgeon, in the fascial and subcutaneous tissues of the surgical wound. Additional analgesia: acetaminophen $1 \mathrm{~g}$ every $8 \mathrm{~h}$. Postoperative pain at rest (PR) and with movement (PM) were recorded at 8,12 and 24 hours after surgery, using NRS scale for pain.

\section{RESULTS}

Postoperative PR was 2 and postoperative PM was 3 control during the first 24 hours after surgery. No rescue opioids or fans required.

\section{CONCLUSIONS}

We believe that the combination of this analgesic procedure and LIA could be considered a useful part of a multimodal analgesic treatment for post-operative pain after the hip replacement surgery, for the best opioid-sparing strategy and fast-track recovery.

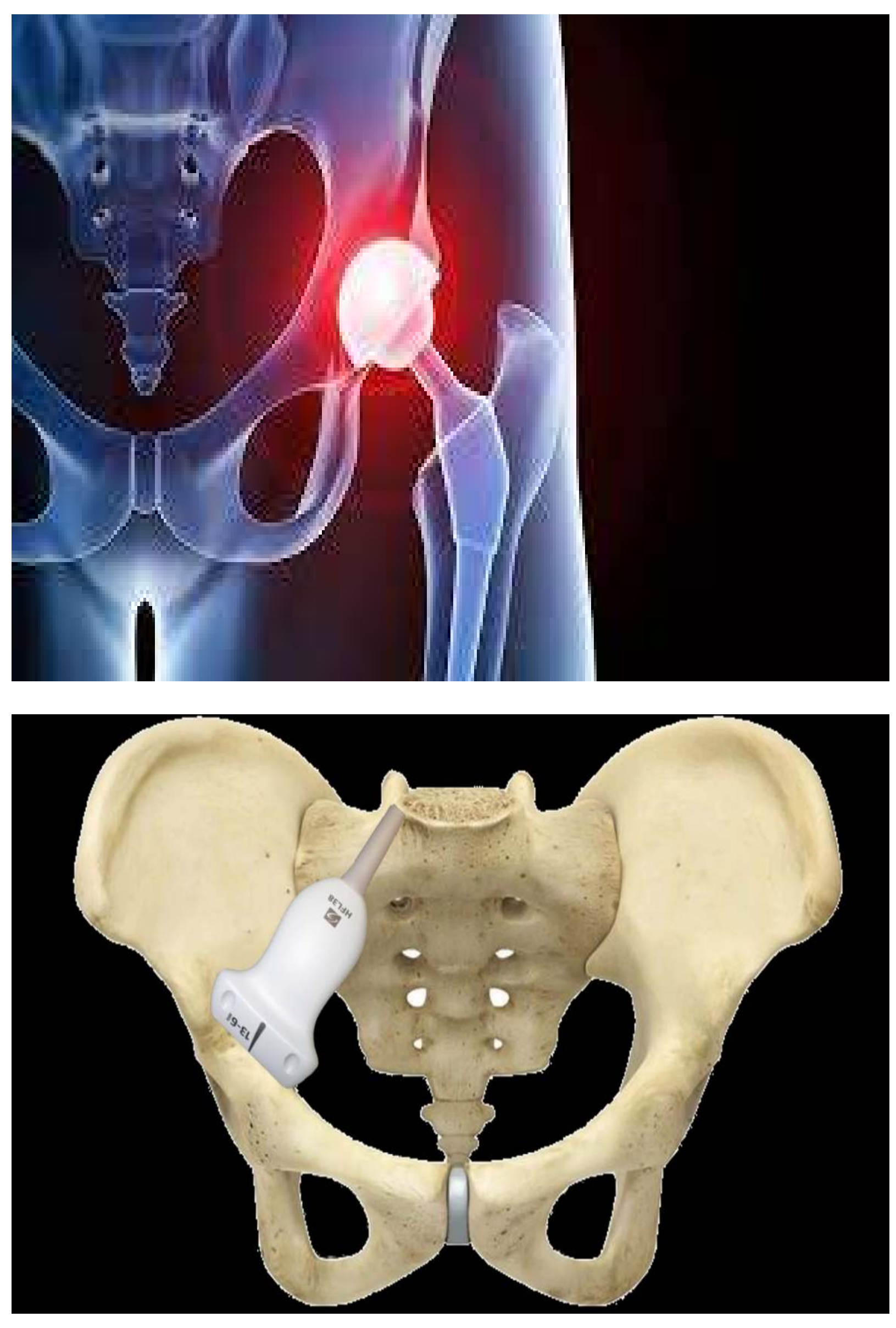

PENG block ultraspund approach

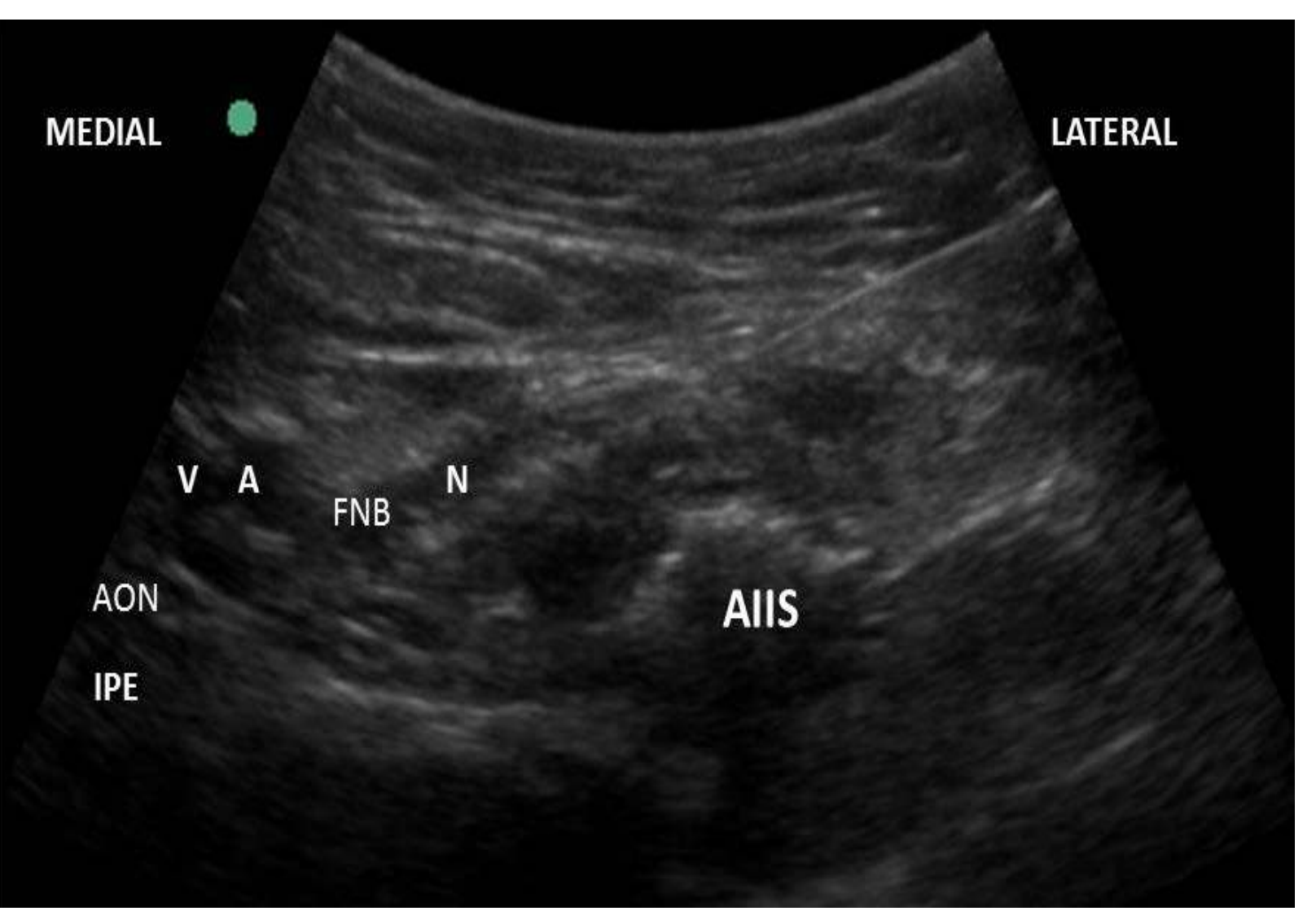

PENG block ultraspund imagine. V, Femoral Vein; A, Femoral Artery; N, Femoral Nerve; FNB, Femoral Nerve Branches AON, accessory obturatory nerve; AIIS, Antero-Inferior Iliac Spine; IPE, Iliopubic eminence; 